\title{
Development of Total Uranium Analytical Method by L X-Ray Fluorescence
}

by

\section{R. A. Dewberry}

Westinghouse Savannah River Company

Savannah River Site

Aiken, South Carolina 29808

\author{
DISCLAIMER
}

\begin{abstract}
This report was prepared as an account of work sponsored by an agency of the United States Government. Neither the United States Government nor any agency thereof, nor any of their employees, makes any warranty, express or implied, or assumes any legal liability or responsibility for the accuracy, completeness, or usefulness of any information, apparatus, product, or process disclosed, or represents that its use would not infringe privately owned rights. Reference herein to any specific commercial product, process, or service by trade name, trademark, manufacturer, or otherwise does not necessarily constitute or imply its endorsement, recommendation, or favoring by the United States Government or any agency thereof. The views and opinions of authors expressed herein do not necessarily state or reflect those of the United States Government or any agency thereof.
\end{abstract}

A document prepared for NUCLEAR INSTRUMENTS AND METHODS at , , from -

DOE Contract No. DE-AC09-89SR 18035

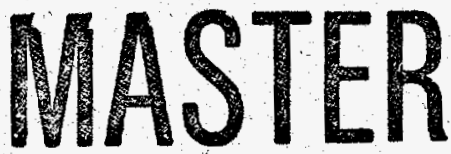

This paper was prepared in connection with work done under the above contract number with the U.S.

Department of Energy. By acceptance of this paper, the publisher and/or recipient acknowiedges the U.S. Government's right to retain a nonexclusive, royalty-free license in and to any copyright covering this paper, along with the right to reproduce and to authorize others to reproduce all or part of the copyrighted paper. 


\section{DISCLAMMER}

Portions of this document may be illegible in electronic image products. Images are produced from the best available original docoment. 


\section{DISCLATMER}

This report was prepared as an account of work sponsored by an agency of the United States Government. Neither the United States Government nor any agency thereof, nor any of their employees, makes any warranty, express or implied, or assumes any legal liability or -responsibility for the accuracy, completeness, or usefiliness of any information, apparatus, product, or process disclosed, or represents that its use would not infringe privately owned rights. Reference herein to any specific commercial product, process, or service by trade name, trademark, manufacturer, or otherwise does not necessarily constitute or imply its endorsement, recommendation, or favoring by the United States Govemment or any agency thereof. The views and opinions of authors expressed herein do not necessarily state or reflect those of the United States Government or any agency thereof.

This report has been reproduced directly from the best available copy.

Available to DOE and DOE contractors from the Office of Scientific and Technical Information, P.O. Box 62, Oak Ridge, TN 37831; prices available from (615) 57.6-8401.

Available to the public from the National Technical-Information Service, U.S. Department of Commerce, 5285 Port Royal Road, Springfield, VA 22161. 
WSRC-MS-96-0569

\section{DEVELOPMENT OF TOTAL URANIUM ANALYTICAL METHOD \\ BY L X-RAY FLUORESCENCE}

R. A. Dewberry

Savannah River Technology Center

Westinghouse Savannah River Company

Aiken, SC 29801

\section{ABSTRACT}

This paper describes development of an $L x$-ray fluorescence technique to perform total uranium analysis using an internal excitation source which is added directly to the sample. The method has been demonstrated with synthetic $U$ samples in the limited concentration range of $1 \mathrm{~g} / \mathrm{l}$ to $15 \mathrm{~g} / \mathrm{l}$, and provides the advantages of simplicity, involving no mechanical parts which would normally be found in an external excitation source. Total uranium is determined by counting $L x$-rays fluoresced by a microcurie level spike of Cd-109 added directly to the sample and without shielding the excitation source from the detector. A method for correction of sample self-absorption is included in the analysis.

\section{INTRODUCTION}

This paper describes the development and testing of an $L$-ray fluorescence method of analysis to determine total uranium in samples with $U$ content in the range of $1 \mathrm{~g} / \mathrm{l}$ to $15 \mathrm{~g} / \mathrm{l}$ and $\mathrm{Pu}$ content less than $10 \mathrm{mg} / \mathrm{l}$. The technique described uses a spike of about $2 \mu \mathrm{Ci}$ of $C d-109$ internal to the sample to fluoresce the $U$ L $X$-rays and therefore does not require an external $x$-ray fluorescence device or external $C d-109$ source. The technique of $x$-ray fluorescence is well known, and diverse analytical instruments exist which provide anaylsis of multiple elements at a time, including uranium 1 . These instruments use external exitation devices and generally are designed to measure each element by fluorescence of the $K x$-ray doublet. At the Savannah River Site we have developed and demonstrated an on-line type instrument which uses a co-57 source to excite the $K x$-rays to measure total uranium in the prescence of $\mathrm{Pu}$ and several fission products ${ }^{2}$. In each case for these instruments it has been necessary to expose the sample to the excitation source and then to remove the source behind a shield so that the instrument's detector is not exposed to it.

The use of $C d-109$ as an excitation source for the $U L$ L-rays is especially advantageous. Its decay produces the five $x$-ray and $\gamma$-ray transitions listed in Table 1. The Cd-109 transitions near $22 \mathrm{kev}$ are just above the L electron absorption edge for uranium $(21.8 \mathrm{keV})$, and so they are particularly suited to ionize the $L$ electrons and to fluouresce the uranium $L$-rays. Yet they are not energetic enough to fluoresce the $L x$-rays of any of the $Z>92$ elements, and we can expect to obtain active $L$ fluorescence spectra which are very clean of anything but the uranium transitions. 
In the technique we describe here, the Cd-109 spiked activity is introduced directly into the liquid sample, and the sample and excitation source are counted simultaneously. The cross section for ionization of the $U \mathrm{~L} x$-rays is large enough that we are able to count the fluoresced $L$ x-rays without shielding the detector from the Cd-109 spiked activity. The advantages of this technique over others sensitive in this range are simplicity, speed, and that this technique empirically subtracts interferences. If the Pu content is low, no chemical preparation of the sample is necessary. No interaction with the counting instrument is necessary after the analysis is initiated.

Note we require that the Pu content of the sample is very low. Pu $\alpha$-decays to $U$ and produces large quantities of the $U L \mathrm{~L}$-rays, which are the same photons we wish to count in this fluorescence analysis. Since all $\mathrm{Pu}$ isotopes decay with half-lives much shorter than either of U-235 or U-238, atom contents of $\mathrm{Pu}$ up to $1 / 100^{\text {th }}$ of the $\mathrm{U}$ atom content would result in significant interference in this analysis. One mitigating factor in this interference is that the $\mathrm{L} \times$-rays from $\mathrm{Pu}$ decay are passive transitions and do not contribute to the active fluorescence spectrum. Thus the passive $U L$-rays are part of the blank sample spectrum and can be easily background subtracted from the active spectrum.

In the event that the Pu content of the sample is too large, no bias is introduced in the analysis. Rather the imprecision in the measurement begins to dominate the results. That is the subtraction of the passive background spectrum from the active spectrum represents the difference of two large numbers to yield a net small number. Thus a large uncertainty in the data obtained signals that the sample must be further treated to remove $\mathrm{Pu}$.

\section{PRINCIPAL OF MEASUREMENT}

The mode of fluorescence used in this technique of analysis is depicted in Figure 1. Cd-109 decays with a 463-day half-life to excited states of Ag-109; emitting $K x$-rays with energies of $21.990-, 22.163-$, and $25.603-\mathrm{keV}$ and $a$ $\gamma$-ray of energy $88.034-\mathrm{keV}$. The two lowest energy $K$-rays are particularly suited in energy to fluoresce $U \mathrm{~L} x$-rays. The $x$-ray absorption cross section for this fluorescence can be estimated from available data ${ }^{3}$ to be $43 \mathrm{~cm}^{2} / \mathrm{g}$. Thus a $1 \mathrm{~g} / \mathrm{l} U$ solution with $a 1 \mathrm{~cm}$ absorption path length will absorb these $K$ $x$-rays at the rate

$$
I=I_{0} \exp [(-1)(43)(0.001)]=0.958 I_{0} \text {, }
$$

where $I_{0}$ is the initial intensity of $\mathrm{Cd}-109 \mathrm{~K} x$-rays. The fluorescent yield for these $L$-ray holes is approximately $0.51(4)$, so the rate of production of $L$ X-rays from a $1 \mu \mathrm{Ci}$ spike of $\mathrm{Cd}-109$ is

$$
0.51(1-0.958)\left(3.7 \times 10^{4}\right)=790(\mathrm{U} \mathrm{L} \times \text {-rays }) / \mathrm{sec} .
$$

Thus the ratio of $U \mathrm{x}$-rays to transmitted Ag x-rays is in the range of 0.02 , and we can count the fluoresced $L x$-rays in the presence of the excitation source without shielding the detector from the source. The energies and relative intensities of the $U \mathrm{~L} x$-rays obtained are shown in Table 2 . 
Since the technique is based on the sample absorption of $22 \mathrm{keV}$ $x$-rays, it is obvious that the fluoresced $L$ x-rays of approximately $17 \mathrm{keV}$ $x$-rays will themselves be strongly self-absorbed by the sample. We require a method to measure the sample self-absorption and to correct for it. We describe our sample self-absorption correction below based on the approach used in reference 5 .

\section{EXPERIMENT AND RESULTS}

To demonstrate the fluorescence technique we made five $\mathrm{U}$ solutions in $2 \mathrm{M} \mathrm{HNO}_{3}$ with $U$ contents of $1-, 4-, 6-, 8-$, and $15-\mathrm{g} / \mathrm{l}$. Then $5 \mathrm{ml}$ aliquots of each were pipetted into plastic vials of $25 \mathrm{ml}$ capacity. The vials are screw cap items with a 4-cm circular base and a wall thickness of $2 \mathrm{~mm}$. They are designed to sit on an up-looking photon detector to provide maximum surface exposure of the liquid sample to the detector active area and to minimize absorption of photons by the vial.

Each of the samples was placed on the up-looking surface of a Si(Li) Low energy photon detector with an active surface area of $80 \mathrm{~mm}^{2}$ and an operating voltage of $-1000 \mathrm{~V}$. The detector had a $2 \mu \mathrm{Ci}$ Fe-55 source implanted in it to produce a doublet of $\mathrm{K} x$-rays at $5.9 \mathrm{keV}$ and $6.5 \mathrm{keV}$ to assist in energy calibration. A $300 \mathrm{sec}$ passive x-ray spectrum of the energy range $5 \mathrm{keV}$ to 30 $\mathrm{keV}$ was taken for each sample and stored in the 2048 channel memory of a Canberra Series 90 Multichannel Analyzer (MCA).

Each sample was then spiked with $50 \lambda$ from a $40 \mu \mathrm{Ci} / \mathrm{ml} \mathrm{Cd-109}$ source and counted in the same configuration [shown in Figure 2(a)] for $1000 \mathrm{sec}$. A blank sample was also spiked and counted. The spectrum obtained for the $8 \mathrm{~g} / \mathrm{l}$ sample is shown in Figure 3. Note in the figure that an MCA deadtime of only 3.4\% was obtained. The previously stored background spectrum was then normalized to 1000 seconds and subtracted channel by channel from the active spectrum. For each of the resulting spectra, the area under the 13.6-, 16.6-, and $17.2-\mathrm{keV} L \mathrm{x}$-ray peaks was summed. Also the area under the $\mathrm{Cd}-109$ 22.2-keV $\mathrm{K} x$-ray peak was obtained. The ratio between these two quantities is tabulated as $x_{s}$ in Table 3 .

The data of $x_{s}$ are shown plotted in Figure 4 in the lower curve. As expected, the curve is significantly concave downward due to the sample self-absorption of the uranium $L$ x-rays. It is clear that sample absorption of $L$-rays causes a negative bias in the detected fluorescence rate as the $U$ content increases.

To correct for the sample self-absorption effect, we constructed a vial as shown in Figure $2(b)$. This vial has a 2 gram sample of natural uranium glued by epoxy to the under surface of the screw cap. The uranium foil was suspended $1 \mathrm{~cm}$ above the surface of the sample, and the active $L \mathrm{x}$-ray spectrum was again collected for $1000 \mathrm{sec}$ for each sample and for the blank with the foil in place. This $U \mathrm{~L} x$-ray to $\mathrm{Ag} K \mathrm{~K}$-ray ratio is tabulated in Table 3 as $x t$. 
In the configuration of Figure $2(b), A g K x$-rays escape the sample and fluoresce the $U L x$-rays in the $U$ foil in the same mechanism that occurs in the sample. These foil-fluoresced $L x$-rays must then traverse the sample to reach the detector, and in this way the active spectrum is a sum of sample fluorescence and foil fluorescence. Since sample $x$-rays and foil $L$-rays both suffer from sample absorption, this technique of analysis provides a very good method of empirically subtracting the effect of sample self-absorption.

Using the method of reference 5 for photon transmission, we calculate transmission correction factors and corrected detection rates for each sample as shown in the following. We determine the sample self-absorption factor $\alpha(i)$ for each sample from

$$
\alpha(i)=\frac{x_{t}(i)-x_{s}(i)}{x_{o}}
$$

where $x_{0}$ is the $x_{t}$ value obtained for the blank.

For example, since $x_{t}$ for sample 1 is 0.02360 , and $x_{S}$ is 0.01246 , and $x_{0}$ is 0.01397 , then

$$
\alpha(i)=\frac{0.02360-0.01246}{0.01397}=0.7974
$$

We then determine a correction factor $C F(i)$ for each sample by

$$
C F(i)=\frac{-\ln \alpha(i)}{1-\alpha(i)}
$$

So the correction factor for sample 1 is 1.117 . The corrected fluorescent yield for each sample is

$$
C C(i)=C F(i) \times \times s(i) \text {, }
$$

where $C C(i)$ is the corrected count ( $L$ to $K$ ratio) of sample $i$, and $C F(i)$ is the calculated correction factor. Equations (3) through (5) are derived in reference 5 pages $\mathrm{I}-1$ through $\mathrm{I}-12$.

The resulting corrected count data are plotted in Figure 4 in the upper curve. These data show that the correction has straightened the fluorescence curve. The difference between the two curves demonstrates the magnitude of the selfabsorption effect, which in the case of the $15 \mathrm{~g} / \mathrm{l}$ sample is greater than a factor of two correction. 


\section{CONCLUSION}

This experiment has demonstrated the utility of the $\mathrm{L}$-ray fluorescence analysis of uranium using an internal excitation source spike in the sample. The samples in the range of $1 \mathrm{~g} / \mathrm{l}$ to $15 \mathrm{~g} / \mathrm{l}$ can be determined with an overall counting time of less than one hour. The fluorescence absorption cross section for uranium using 22.1-keV x-rays as the excitation source is so large $\left(43 \mathrm{~cm}^{2} / \mathrm{g}\right)$ that the detector can be exposed to the excitation source without causing an unacceptable dead time.

This technique requires no chemical treatment of the sample when it contains less than $\sim 0.1 \mathrm{~g} \mathrm{Pu} / \mathrm{l}$. The only operator interaction with the analysis instrument is initiation of each count. With preparation the multichannel analyzer of the instrument can be set up to automatically store the data in the appropriate memory segment, acquire the active spectra, perform background subtraction, and provide the required ratios $x_{s}, x_{t}$, and $x_{0}$ for each sample run, with one task command. It can also be set up to calculate and display the precision obtained for each measurement.

The advantages that this technique of $U$ determination provide over matrix dependent techniques and over external excitation source fluorescence techniques are elaborated below.

The system is simple to operate, as no excitation source instrument exists to complicate operation... Initiation of each spectrum collection with a single task command can be the only operator interaction required. The system automatically collects the spectrum, subtracts background, and displays the peak ratio data and errors needed for subsequent calculations using equations (3) through (5) above.

The technique empirically subtracts interferences from $U$ self-absorption and any other matrix absorption effect. Large interferences from too much $\mathrm{Pu}$ in the sample are signalled by large imprecisions in the values $x_{s}$ and $x_{t}$. For samples with large $U L \mathrm{x}$-ray contributions from $P u$ decay, the values $x_{5}$ and $x_{t}$ will be large and very near each other in value. Then the uncertainty in these values will become larger than the difference between them, and the self-absorption factor $\alpha(i)$ calculated in (3) can go negative from random variation.

Using the ratio of $U$ fluorescent yield to transmitted Ag x-rays automatically normalizes the data to remove deadtime corrections and decay of excitation source strength. Thus exact knowledge of the spiked activity is not required. The Cd-109 source has a long (463 day) half-life, thus assuring several years of free excitation.

The data from this experiment have demonstrated the utility of this technique over the limited range of $1 \mathrm{~g} / \mathrm{l}$ to $15 \mathrm{~g} / \mathrm{l}$. 


\section{REFERENCES:}

1. P. E. O'Rourke, D. R. Van Hare and S. R. Salaymeh, "On-Line Analytical Systems for the U Solidification Facility at SRS," Proc. of 31st Annual Meeting of the Inst. of Nucl. Materials Management, Los Angeles, 1990.

2. R. F. Parry, R. A. Johns, V. W. Walker, R. A. Camp, D. C. Ruther, and D. Ekels, DP-MS-85-77, Savannah River Plant external report, Octobr 1985.

3. CRC Handbook of Chemistry and Physics, 68th Edition. (Ed. Robert C. Weast. CRC Printing, Inc. Boca Raton, FL 1987.). E-139 to E-142.

4. E. Browne and R. B. Firestone, Table of Radioactive Isotopes, (WileyInterscience, New York, 1986).

5. Advanced Gamma-Ray Spectroscopy for Nuclear Materials Accountability. (U. S. Department of Energy Training Program, Los Alamos National Laboratory, December 1986).

Table 1

Energies and relative intensities of photons emitted by $\mathrm{Ag}-109$ following decay of Cd-109. Energies are in units of keV.

Photon Eneray

21.990

22.163

24.934

25.603

88.034

\section{Relative Intensity}

28.9

54.5

13.7

2.72

3.6 
WSRC-MS - 96-0569

18 September page 7 of 11

Table 2

Energies and relative intensities of Uranium $L \quad x$-rays observed by $L$-shell vacancies produced by fluorescence from $\mathrm{Cd}-109$ decay. Energies are in units of $\mathrm{keV}$.

\begin{tabular}{cr} 
Photon Energy & Relative Inte \\
\hline 13.619 & 3.4700 \\
15.400 & 0.0268 \\
15.727 & 0.0154 \\
16.410 & 0.1805 \\
16.577 & 0.0276 \\
17.069 & 0.0046 \\
17.222 & 1.0000 \\
17.454 & 0.0105 \\
20.169 & 0.2429
\end{tabular}

Table 3

Fluorescent yield data and corrected yield results for liquid $U$ samples in the range $1 \mathrm{~g} / \mathrm{l}$ to $15 \mathrm{~g} / \mathrm{L}$. The uncorrected data are tabulated as $X_{S}$, and the corrected data are tabulated as CC. The sample plus $U$ foil data are tabulated as $x t$. The correction factors are listed in the fourth column as CF.

Corrected and uncorrected yields are explained in the text.

U

$(a / 1)$

0

0.992

3.970

6.000

7.937

15.00 $x_{s}$

(no units)

0.01246

0.03976

0.05600

0.07300

0.11187 $x_{t}$

(no units)

0.01397

0.02360

0.04730

0.06319

0.07627

0.11400
CF (no units)
CC (no units)
1.000

1.117

1.340

1.369

1.896

2.219
0.01397

0.01392

0.05327

0.07664

0.1384

0.24826 


\section{Total Uranium Determination}

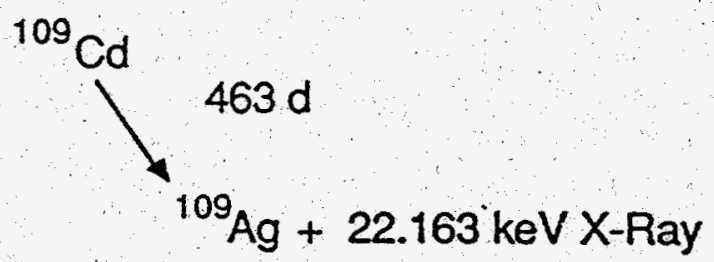

FIGURE 1. Schematic Representation of U L X-Ray Fluorescence by 109 Cd Decay 

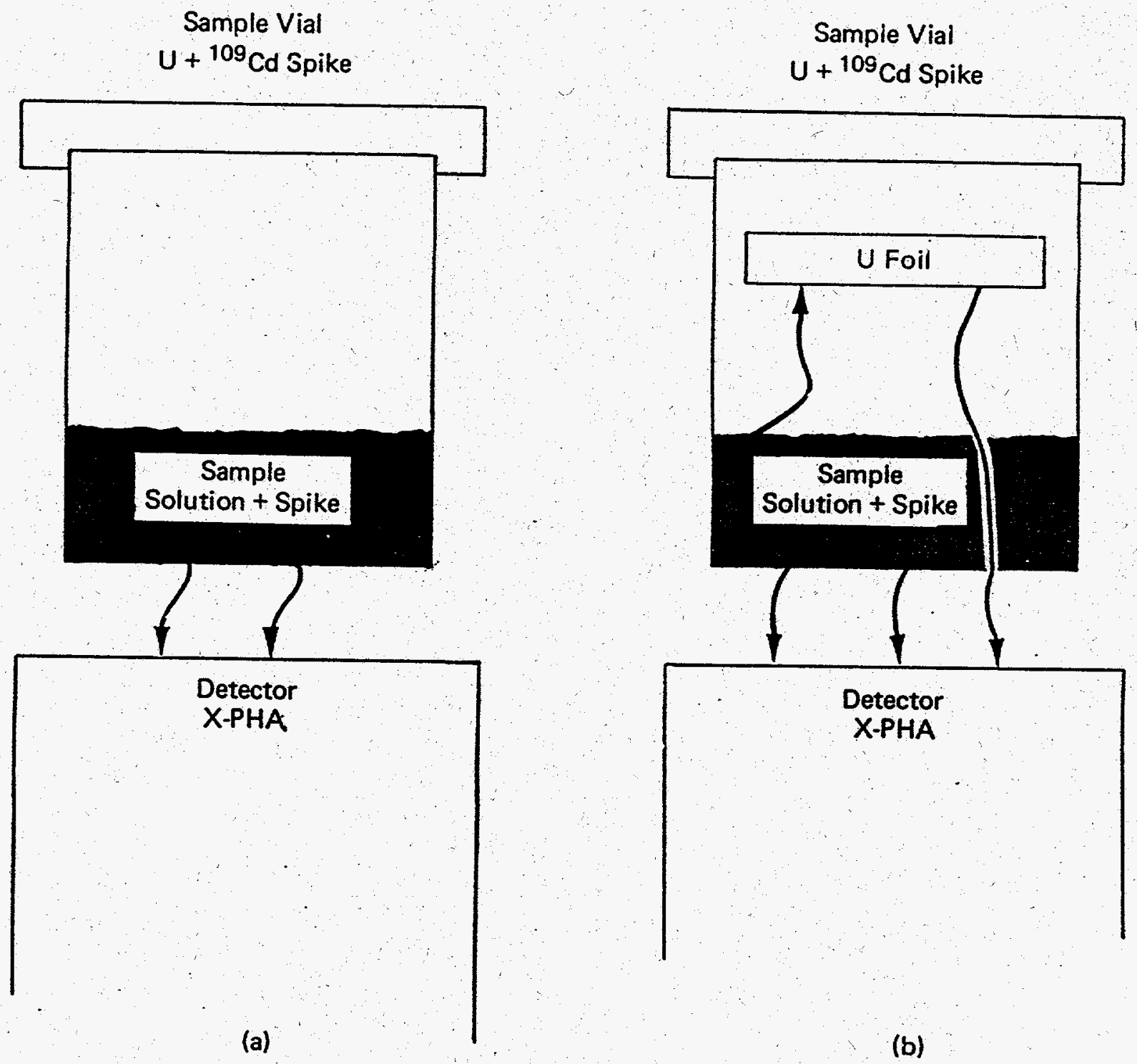

FIGURE 2. Counting Configurations for Obtaining Uncorrected Data (a) and Self-Absorption Corrected Data (b) 


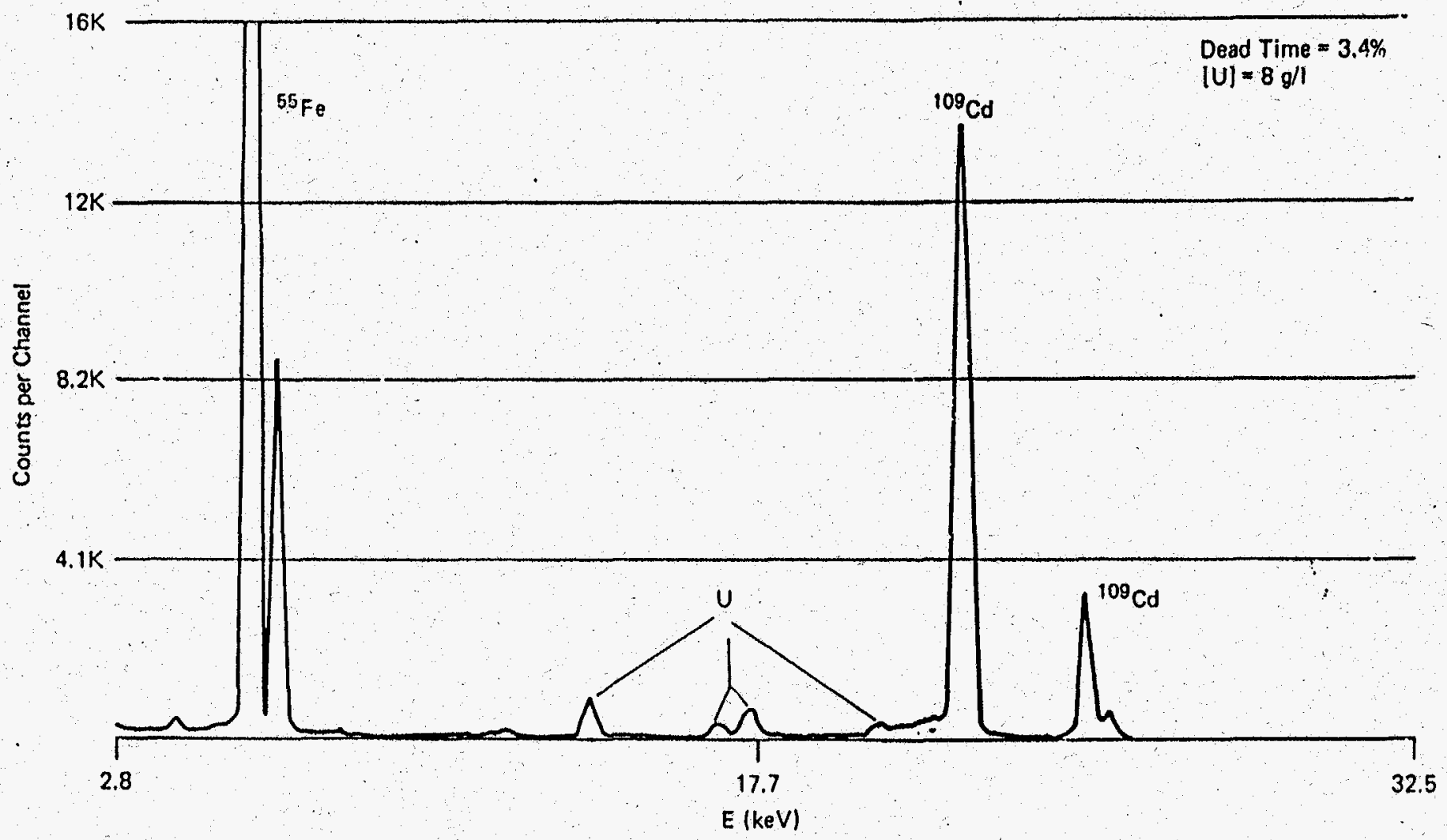

FIGURE 3. ULX-Ray Spectrum Obtained using the Counting Configuration of Figure 2(a) with an $8 \mathrm{~g} / 1$ U Solution and a $2 \mu \mathrm{Ci}{ }^{108} \mathrm{Cd}$ Spike in the Sample as Described in the Text 


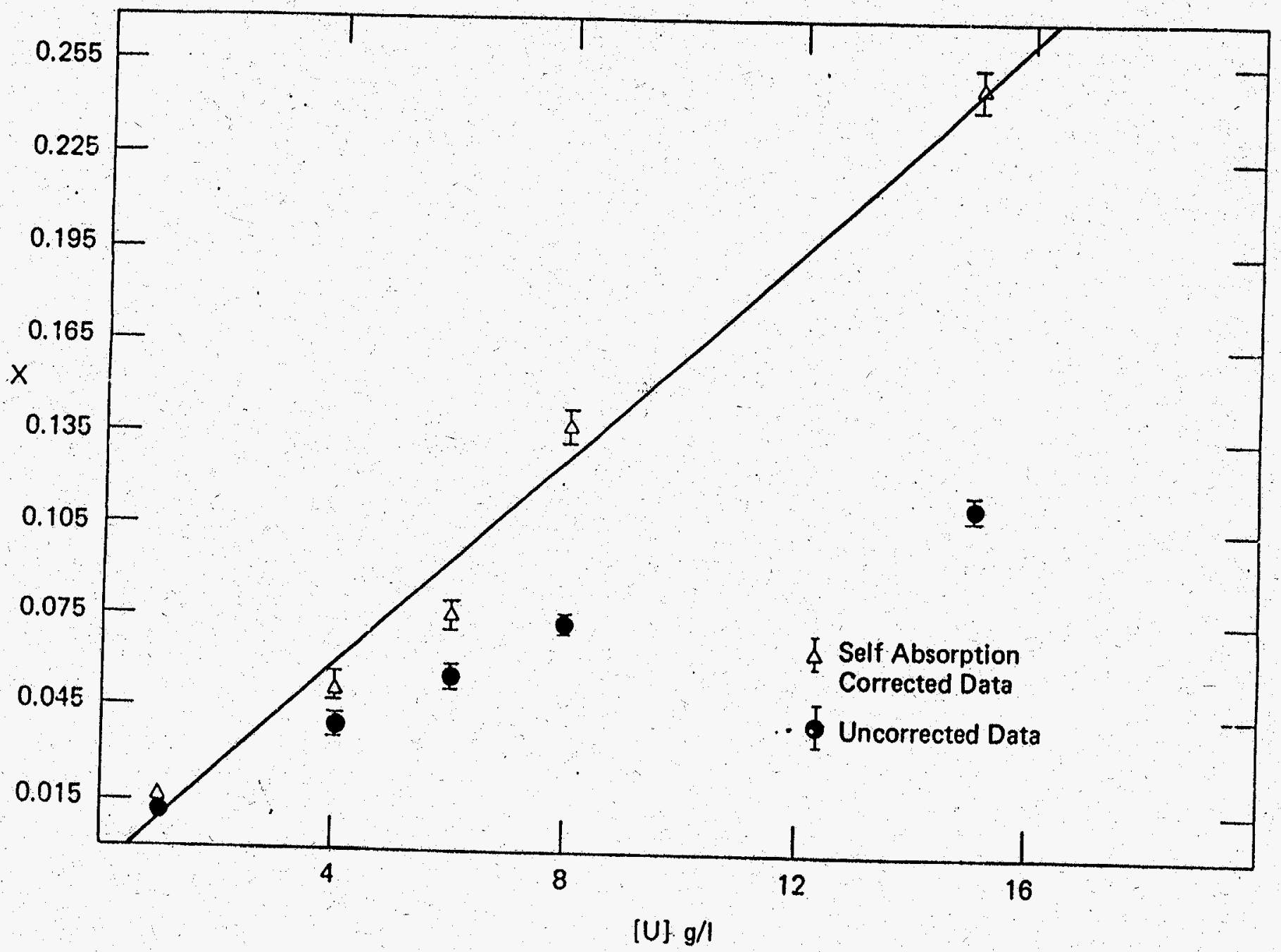

FIGURE 4. Linear Plots of the Corrected and Uncorrected U L X-ray Fluorescence Yield 